\title{
Library to deacidify books
}

\section{Washington}

THE Eisenhower Library at Johns Hopkins University in Baltimore is starting an innovative programme to save thousands of books threatened by the acid in their pages. At a cost of nearly $\$ 11$ per volume, the books will be deacidified with a 60 hour treatment in a vacuum chamber filled with diethyl zinc (DEZ) gas.

Officials at Hopkins and at Akzo Chemicals, the company providing the service, say that, as far as they know, this is the first time a library in the United States has undertaken such a mass deacidification campaign.

Most books printed since 1800 have been made with paper that has a high acid content which, over the years, causes the pages to become brittle and eventually crumble into dust. Saving those books is expensive - it can cost $\$ 100$ a book or more to copy them onto microfilm, and a custom preservation job in which a book is taken apart and restored page by page costs about $\$ 1,000$ a volume.

So, in the mid-1970s, scientists at the Library of Congress began to look for an alternative. They developed a process that uses gaseous DEZ to penetrate the pages of books and react with any acids to form neutral salts. In addition, the DEZ reacts with any residual water in the paper to form zinc oxide, which remains in the paper as a 'buffer' to counteract any acid that attacks the pages in the future. The process was licensed to Akzo, which had supplied the DEZ for the development.

Akzo spokesman Dick Miller says tests indicate that books treated with $\mathrm{DEZ}$ will last three to five times longer than untreated books, which usually have a lifetime of 50 to 100 years.

When the company begins truly largescale programmes, where thousands of books are treated at a time, the cost per book should drop to between $\$ 6$ and $\$ 10$, he says.

Over the next year, the Johns Hopkins library plans to send about 300 books per month to Akzo, most of them foreign language paperbacks published outside the

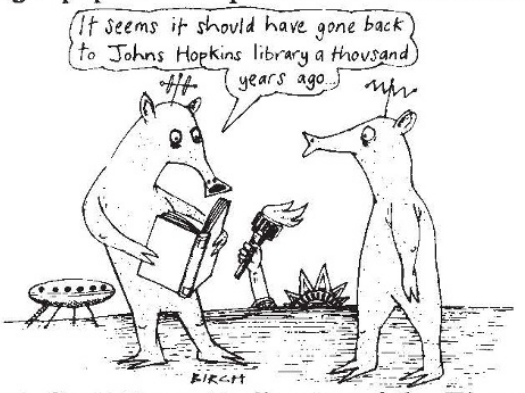

West. Scott Bennett, director of the Eisenhower Library, explains that these books tend to be printed in limited printing runs on very acidic paper, so that they are among the hardest books to replace.

Akzo is hoping to land a contract with the Library of Congress, which is under congressional mandate to deacidify millions of books in the coming decade. Although Library of Congress scientists developed the DEZ method, the library is also considering two deacidification processes that use liquid treatment to neutralize the acid in the pages. "Many people (at other libraries) are watching to see what the Library of Congress decides," Miller says.

Robert Pool

\section{Moon base best, says panel}

\section{Washington}

From the rapidly shrinking list of reasons to build the US-led international space station, subtract one more. Given the increasingly likely prospect of a delayed and underequipped station, a lunar orbiter and a moon base might provide better preparation for the Mars mission now being planned, a blue ribbon panel commissioned by the National Aeronautics and Space Administration (NASA) has concluded.

Scientists could use existing vehicles such as the space shuttle and the Soviet Mir station for life-science research over the next decade or so, according to portions of the panel's report leaked last week. Eventually, researchers could move to stations in lunar orbit and a lunar base in order to study human adaptability to the long-term weightlessness of space travel and the one-third Earth gravity of Mars, the report says.

The panel, headed by former US general Thomas Stafford, was assembled last year to take a fresh look at the NASA's planned
Moon/Mars initiative and to solicit new ideas from outside the government and the usual contractors (see Nature 345, 651; 21 June 1990). It intends to release its full report next week at a press conference.

If the space station can be built in time and at full capacity, it would be the preferable platform for much of the life science research, the panel said. But as NASA reduces the station's capacity in an effort to cut costs and fight a threatened congressional cancellation, the panel suggested that "it is logical to consider the Moon" as a viable alternative.

Such faint praise for the space station will hardly improve the job of the NASA officials now fighting to save the troubled project in the face of congressional opposition. Life science research is one of the station's remaining scientific missions. The suggestion that even that could be done well elsewhere leaves NASA with less justification for the $\$ 30,000$ million project, congressional staff say. Christopher Anderson

\section{A stress-cancer link following accident?}

Washington

A SMALl wave of excess cancers occurred three years after the 1979 Three Mile Island nuclear accident among people living close to the plant, according to a report published in the American Journal of Public Health $(81,719-724 ; 1991)$, but the increase in cancers was not caused by radioactivity released during the mishap. Instead, the authors suggest, the culprit could have been either stress or simply increased attention towards health concerns.

The research team, led by Maureen Hatch of the Columbia University School of Public Health in New York City, examined cancer rates after the accident as a function of distance from the plant: less than $6 \mathrm{~km}$, between 6 and $12 \mathrm{~km}$ and between 12 and $22 \mathrm{~km}$. Among people in the latter two groups, cancer rates remained unchanged, but the researchers found an increase in cancer incidence among the first group.

Cancer rates for those people increased by about 50 per cent in 1982 and remained higher than normal in 1983, but by 1985 the incidence rate had fallen below the historical average. "The pattern is quite striking and is unlike anything that had appeared previous to the accident," Hatch says.

The study included all types of cancers.

Hatch and co-workers rule out increased radioactivity as a cause for the increased cancer incidence because of a study they published last September in the American Journal of Epidemiology 132, 397-412; 1990).

There they compared cancer rates around Three Mile Island with recorded levels of radioactivity and found no significant correlation. The results were unsurprising because scientists already believed that the very low levels of radioactivity released by the accident were unlikely to have a measurable effect on cancer rates.

If the current findings are not just a statistical anomaly, Hatch believes the most reasonable explanation for them is that people living near the plant felt heightened stress in the months and years after the accident. This stress could have triggered increased cancer growth directly - a hypothesis that most researchers believe to be highly speculative - or it could have acted indirectly. Hal Morgenstern, an epidemiologist at the University of California, Los Angeles, notes that studies have shown stress causes people to be more likely to recognize and report various symptoms and to seek care for them.

In that case, the Three Mile Island accident could actually have done some people living close to the plant a favour by leading them to detect existing cancers sooner than they would have otherwise.

Robert Pool 